\title{
Metal-boride phase formation on tungsten carbide (WC-Co) during microwave plasma chemical vapor deposition
}

\author{
Jamin M. Johnston ${ }^{\mathrm{a}}$, Shane A. Catledge $\mathrm{a}^{\mathrm{a}, *}$ \\ ${ }^{a}$ Department of Physics, University of Alabama, Birmingham, AL 35294-1170, United States \\ *Corresponding author: \\ Shane A. Catledge \\ 310 Campbell Hall \\ 1300 University Boulevard \\ Birmingham, AL 35294-1170 \\ Phone: (205) 934-3693 \\ E-mail: catledge@uab.edu
}

\begin{abstract}
Strengthening of cemented tungsten carbide by boriding is used to improve the wear resistance and lifetime of carbide tools; however, many conventional boriding techniques render the bulk carbide too brittle for extreme conditions, such as hard rock drilling. This research explored the variation in metal-boride phase formation during the microwave plasma enhanced chemical vapor deposition process at surface temperatures from 700 to $1100{ }^{\circ} \mathrm{C}$. We showed several welladhered metal-boride surface layers consisting of $\mathrm{WCoB}, \mathrm{CoB}$ and/or $\mathrm{W}_{2} \mathrm{CoB}_{2}$ with average hardness from 23-27 $\mathrm{GPa}$ and average elastic modulus of 600-730 $\mathrm{GPa}$. The metal-boride interlayer was shown to be an effective diffusion barrier against elemental cobalt; migration of elemental cobalt to the surface of the interlayer was significantly reduced. A combination of glancing angle x-ray diffraction, electron dispersive spectroscopy, nanoindentation and scratch testing was used to evaluate the surface composition and material properties. An evaluation of the material properties shows that plasma enhanced chemical vapor deposited borides formed at substrate temperatures of $800{ }^{\circ} \mathrm{C}, 850{ }^{\circ} \mathrm{C}, 900{ }^{\circ} \mathrm{C}$ and $1000{ }^{\circ} \mathrm{C}$ strengthen the material by increasing the hardness and elastic modulus of cemented tungsten carbide. Additionally, these boride surface layers may offer potential for adhesion of ultra-hard carbon coatings.
\end{abstract}

Keywords Boriding, Ternary Boride, Thin-film, Cemented Carbide, Tungsten Carbide 


\section{Introduction}

Cemented tungsten carbide (WC-Co) is a high strength, high hardness sintered ceramic composed of tungsten, carbon, and cobalt. The exact percentages of these elements vary depending on desired properties. Due to the sintering process small amounts of oxygen and nitrogen are also present in the porous ceramic structure[1]. Tungsten carbide is one of the most durable materials available for mining, drilling and cutting operations. Despite the incredible hardness, a carbide bit can wear down in seconds[2]. In the ongoing search for better industrial materials, boriding and diamond coatings are viable solutions to reduce wear and increase tool life[3, 4]. Unfortunately, unlike many existing diamond coating processes, well adhered diamond cannot be grown directly onto cemented tungsten carbide alloys due to graphitic nucleation caused by the presence of cobalt $[5,6]$. To this end, boride treatments have been explored as a means to strengthen materials, both as an individual metal-boride surface layer and as an interlayer for nanostructured diamond[5-9].

Boriding is widely used to improve material properties, and can be successfully implemented as a surface treatment for diamond deposition in an array of materials, including tungsten carbide[9,10]. Boriding is shown to result in higher hardness and improved durability when compared to other surface modifications, such as, carburizing or nitriding[11-13]. Transition metal borides $\left(\mathrm{TiB}_{2}, \mathrm{ZrB}_{2}, \mathrm{Fe}_{2} \mathrm{~B}\right.$ and $\left.\mathrm{Co}_{2} \mathrm{~B}\right)$ are good candidates for diamond deposition; they are stable, compatible with carbon, densely packed, and inhibit carbon diffusion[3, 13]. Significant research has been conducted on the boriding process, but there are still gaps in existing knowledge. Most boriding research for tungsten carbide has been performed using conventional chemical vapor deposition (CVD), molten salt, or powder packed methods for longer time periods from 4 to 12 hours with typical temperatures at or over $1000{ }^{\circ} \mathrm{C}$ [14-17]. Research using plasma enhanced chemical vapor deposition (PECVD) boriding, shorter time durations, and lower temperatures is relatively unexplored. Furthermore, an analysis of boride phase transitions with smaller $\left(50 \mathrm{C}^{\circ}\right)$ increments from $700{ }^{\circ} \mathrm{C}-1100{ }^{\circ} \mathrm{C}$ for PECVD has not been previously performed.

Recently, we have shown that microwave PECVD is an effective method for thermochemical surface modification using diborane $\left(\mathrm{B}_{2} \mathrm{H}_{6}\right)$ in the feedgas to form metal-boride surface layers on cobalt-chromium alloys[18]. These borides often include orthorhombic CoB and bodycentered tetragonal $\mathrm{Co}_{2} \mathrm{~B}$ structures, among others. PECVD boriding of tungsten carbide can also form the less explored ternary borides $\left(\mathrm{WCoB}, \mathrm{W}_{2} \mathrm{CoB}_{2}\right.$ and $\left.\mathrm{W}_{3} \mathrm{CoB}_{3}\right)$ with reported hardness ranging from $23.4 \mathrm{GPa}[11]$ to $45 \mathrm{GPa}[19]$. In the current work, we explore the formation of borides on tungsten carbide during PECVD using diborane and a range of substrate temperatures. Material properties of metal-boride layers, including ternary borides, without diamond deposition are investigated.

\section{Experimental methods}

\subsection{Sample Preparation}

The WC-Co investigated here was a TM6 grade sintered carbide composed of 94\% WC, $6 \%$ Co binder; carbides had a known hardness of 89.6-90.4 (Ra) and 1500-2000 (Hv), density of 
$14.95\left(\mathrm{~g} / \mathrm{cm}^{3}\right)$, and a medium grain size[20]. The carbide bits measured $10 \mathrm{~mm}$ diameter by $3 \mathrm{~mm}$ height. Prior to boriding bits were polished at $350 \mathrm{rpm}$ for 10 minutes with each of 125, 70, 30, 15 and 9 micron metal-bonded diamond pads, and then polished with diamond solution at 9, 6, 3, and 1 microns for 30 minutes at each size. Polished samples were then cleaned via sonication with acetone and then methanol for 20 minutes each, followed by a deionized water rinse.

Post-boriding, sample cross sectioning was performed with an Allied High Tech Techcut 4 low speed metal sectioning tool. Samples were mounted in epoxy to increase edge retention, then sectioned using a 6 inch diameter resin bonded diamond wafering blade at $300 \mathrm{rpm}$. After sectioning, the cross-sectional surface was polished at $350 \mathrm{rpm}$ for 10 minutes with each of 70 , 30, 15 and 9 micron metal-bonded diamond pads, and then polished with diamond solution on Allied Tech-Cloth pads at 9, 6, 3, and 1 microns for 30 minutes at each size. Polished samples were then cleaned with an acetone rinse followed by deionized water.

\subsection{Boriding}

A $2.45 \mathrm{GHz}$ microwave-plasma CVD (Wavemat, Ann Arbor, MI, USA) chamber was utilized. Boriding was performed with a diborane $\left(\mathrm{B}_{2} \mathrm{H}_{6}\right)$ and hydrogen $\left(\mathrm{H}_{2}\right)$ feedgas mixture consisting of $500 \mathrm{sccm}$ of high purity $99.9 \%\left(\mathrm{H}_{2}\right)$ and $3.0 \mathrm{sccm}$ of $\mathrm{B}_{2} \mathrm{H}_{6}$ (provided as a $10 \%$ dilution in $\mathrm{H}_{2}$ ). Pressure and power were incrementally increased until the desired trial specific parameters were met, typically between 30-60 Torr and .6-1.5 kW. Substrate temperature was measured using a two-color optical pyrometer centered at $1.6 \mu \mathrm{m}$. The WC-Co substrate reached a steady state temperature in $\mathrm{H}_{2}$, at which point the combined $\mathrm{H}_{2}$ and $\mathrm{B}_{2} \mathrm{H}_{6}$ feedgas mixture was introduced. Borided WC-Co samples were produced for a range of target substrate temperatures (700-1100 ${ }^{\circ} \mathrm{C}$ at 50 -degree intervals) using a 1 hour duration.

\subsection{Characterization}

X-Ray Diffraction (XRD) patterns were measured using a thin-film diffractometer (X'pert MPD, Philips, Eindhoven, The Netherlands) with $\mathrm{Cu}$ anode $(\lambda=0.154154 \mathrm{~nm})$, generator voltage of $45 \mathrm{kV}$, tube current of $50 \mathrm{kA}$, and glancing angle of $3^{\circ}$. Scans were compared against the Joint Committee on Powder Diffraction Standards database[21], Crystallography Open Database[22], and diffraction simulations using MAUD software[23]. Rietveld refinement was used to evaluate the relative individual phase composition[24].

Scanning electron microscopy (SEM) and energy dispersive spectroscopy (EDS) was done using an FEI QuantaTM 650 field emission gun with $1.2 \mathrm{~nm}$ spatial resolution at $20 \mathrm{kV}$. SEM images were captured in secondary electron mode and EDS line scans were performed on the cross-section of the boride layer to observe change in chemical composition across the interface. It is important to note that boron is within the detection limit for this particular equipment configuration; although boron was near the limit of detection a significant signal was observed. The topography of the coatings was imaged using optical and atomic force microscopy (AFM). AFM images were obtained using contact mode and the roughness values were recorded.

Nanoindentation was performed using a Nanoindenter XP system to evaluate hardness up to a maximum depth of $400 \mathrm{~nm}$. Nanoindentation was performed on the bare alloy and on the 
surface layer after boriding to evaluate changes in hardness and elastic vs. plastic depth. Indents were carried out at a distance of greater than 100 microns from the sample edge, and with an indent separation of at least 25 microns.

Progressive load scratch tests were performed to observe the extent of cracking or delamination of the coatings, determined in accordance with ASTM C1624[25]. Scratch tests were performed with a commercial diamond stylometer (Romulus IV, Quad Group Inc., Spokane, WA, USA) with a $125 \mu \mathrm{m}$ radius spherical diamond tip. The maximum force used was $50 \mathrm{~N}$ with a load rate of $2 \mathrm{~N} / \mathrm{s}$ over a distance of $3 \mathrm{~mm}$. Resulting indents and scratches were examined by optical microscopy to observe cracking and delamination.

\section{Results and Discussion}

\subsection{XRD of WC-Co Boride Layer}

The effects PECVD boriding on WC-Co were investigated across a range of times and temperatures. The crystal phase composition of the WC-Co surface was analyzed using XRD. Figure 1 shows WC-Co borided at $700-1100{ }^{\circ} \mathrm{C}$ at 100 -degree intervals, as well as a control sample which experienced no boriding. The phase analysis was representative for samples prepared at the same temperature. These results show a considerable transition in metal-boride structure with increasing temperature.

This chemical transition is consistent with previous CVD boriding observations[26, 27], but here we provide a more detailed temperature analysis. From Figure 1 it is observed that at $700{ }^{\circ} \mathrm{C}$ there is not sufficient energy to form tungsten boride compounds, so the more readily formed cobalt boride is observed. As temperature increases to $800{ }^{\circ} \mathrm{C}$ tungsten begins to react forming $\mathrm{WCoB}$. It is assumed that at this temperature the reaction of tungsten is still limited preventing the formation of $\mathrm{W}_{2} \mathrm{CoB}_{2}$. At $900{ }^{\circ} \mathrm{C}$ tungsten ions become significantly reactive and in much greater concentration than cobalt, leading to both $\mathrm{W}-\mathrm{B}$ phases and $\mathrm{W}_{2} \mathrm{CoB}_{2}$. The transition from $\mathrm{W}_{2} \mathrm{CoB}_{2}$ to $\mathrm{WCoB}$ is the result of increased cobalt diffusion at even higher temperatures above $900{ }^{\circ} \mathrm{C}$, balancing the excess of tungsten. This relative cobalt concentration seems to increase further at $1100{ }^{\circ} \mathrm{C}$ forming Co-B compounds. Previous CVD boriding results agree well with these observations. A transition from $\mathrm{W}_{2} \mathrm{CoB}_{2}$ to $\mathrm{WCoB}$ has been observed at over $900^{\circ} \mathrm{C}[26,27]$.

A Rietveld refinement[24] was used to evaluate phase composition by percent weight for each sample deposited in the range of $700-1100{ }^{\circ} \mathrm{C}$ at 50 -degree intervals. A plot of surface phase percentage vs temperature, Figure 2, shows a more complete dataset where each point was represented by $n=5$ samples. This reveals the transition from bulk hexagonal WC-Co, followed by masking of surface elemental Co via the formation of various borides, and then the eventual surface etching and re-emergence of $\mathrm{Co}$ at high temperatures. With increasing temperature, formation of boride compounds increased, reducing the presence of tungsten carbide from $94 \%$ to $18 \%$ on the surface. Cobalt boride was observed at temperatures from $700{ }^{\circ} \mathrm{C}$ to $850{ }^{\circ} \mathrm{C}$, but was reduced from $18 \%$ to $0 \%$ as $\mathrm{WCoB}$ and $\mathrm{W}_{2} \mathrm{CoB}_{2}$ phases emerge. At $900{ }^{\circ} \mathrm{C}$ there was a stable maximum for $\mathrm{W}_{2} \mathrm{CoB}_{2}$ at $39 \%$, which was replaced by $\mathrm{WCoB}$ with increasing temperature. At very high temperatures, above $1000{ }^{\circ} \mathrm{C}$, the presence of borides was reduced; 
leading to increased tungsten carbide and hexagonal cobalt phases. This is likely due to increased substrate atom mobility and reduced condensation on the surface for higher temperatures. Of note, the presence of hexagonal cobalt found in the control sample was not present between 700 ${ }^{\circ} \mathrm{C}$ and $850^{\circ} \mathrm{C}$, and existed only in trace amounts until above $1000^{\circ} \mathrm{C}$. For longer time durations above $900{ }^{\circ} \mathrm{C}$, a phase transition from hexagonal Co to cubic Co is expected. Hexagonal and tetragonal $\mathrm{B}_{2} \mathrm{~W}$ phases were observed at $3 \%$ and $4 \%$ composition, respectively, but only for 900 ${ }^{\circ} \mathrm{C}$ (data not shown).

These results indicate that boriding creates a complex set of metal-boride surface layers with a delicate temperature dependence for boride phase formation. For temperatures above 1000 ${ }^{\circ} \mathrm{C}$, etching of surface borides was observed and therefore further investigation of potentially interesting boride phases was not pursued. Temperatures below $800{ }^{\circ} \mathrm{C}$ led to poorly adhered boride soot formation. Temperature conditions with unique boride phase mixtures of interest were found to occur at $800{ }^{\circ} \mathrm{C}, 850{ }^{\circ} \mathrm{C}, 900^{\circ} \mathrm{C}$, and $1000{ }^{\circ} \mathrm{C}$ to form $\mathrm{CoB}$ with $\mathrm{WCoB}, \mathrm{W}_{2} \mathrm{CoB}_{2}$, and $\mathrm{WCoB}$ respectively. In the $800-1000{ }^{\circ} \mathrm{C}$ temperature range, surface elemental cobalt was masked and a sufficient metal-boride surface layer was formed. It is possible that these boride coatings could also be applied for improved growth and adhesion of nano-structured diamond and diamond-like carbon thin films as a result of the masked cobalt.

\subsection{SEM and EDS of WC-Co Boride Layer}

The surface of the boride layer and its cross section were further explored using scanning electron microscopy and energy dispersive spectroscopy. The planar boride surface, Figure 3a, contains micro-fractures and darker pitted regions throughout the explored temperature ranges. Micro-fracturing of the surface is likely caused by residual thermal stress from the deposition process[28, 29]. No adhesive failure or long range fracturing of the film was observed. Pitting could have been a consequence of existing pits in the bulk carbide, a result of fabrication, or the often porous nature of borides[30, 31]. Figure $3 \mathrm{~b}$ and $3 \mathrm{c}$ show the same cross-sectioned surface of a typical PECVD borided WC-Co sample at different magnifications. The upper most surface of the boride layer, is only a few micrometers thick; however, the boriding process also created a deep, graded boron diffusion layer. The diffusion of boron was investigated using an EDS line scan (Figure 3d), indicated by the dashed line (Figure 3b). The line scan confirms boron diffusion into the bulk. Boron concentration decreases with increasing depth into the bulk carbide and peaks at the surface.

The EDS line scan (Figure 3d) shows that the lighter, jagged grains were primarily tungsten, carbon and boron. Interstitial space consists of cobalt binder with boron and reduced tungsten. The surface layer contains a high carbon mixture along with tungsten, cobalt, and boron. In general, tungsten concentration decreases from the bulk to the surface; cobalt, carbon and boron increase from the bulk to the surface. The boron diffusion into the carbide as well as the thermal diffusion of cobalt and tungsten within the carbide give rise to the $\mathrm{CoB}, \mathrm{WCoB}$, $\mathrm{W}_{2} \mathrm{CoB}_{2}$ borides, as seen from XRD (Figures 1 and 2).

The thick graded boron diffusion layer combined with the ternary metal-boride surface coating are promising for applications in material strengthening. Furthermore, a vacancy-assisted 
mechanism is expected to be the primary mode of cobalt diffusion toward the surface[32]. The strong covalent bond energy and the relatively high atomic density of the metal-boride layer should limit the presence of surface cobalt during NSD deposition. The graded boron diffusion layer may be useful for improving adhesion of a subsequently deposited CVD diamond coating by preventing the catalytic graphite-forming interaction of cobalt with carbon on the surface.

\subsection{Surface structure of WC-Co boride}

Optical microscopy was used to characterize the surface structure before and after boriding, and to compare structural changes based on surface temperature. Figure 4 shows the borided surface for samples prepared at $600{ }^{\circ} \mathrm{C}(\mathrm{a}), 800{ }^{\circ} \mathrm{C}(\mathrm{b}), 1000{ }^{\circ} \mathrm{C}$ (c), and $1200{ }^{\circ} \mathrm{C}(\mathrm{d})$. For lower temperatures, below $800{ }^{\circ} \mathrm{C}$, the surface coating appeared as a thick brown soot that was easily removed. At and above $800{ }^{\circ} \mathrm{C}$ the surface formed randomly oriented borides creating a roughened morphology. At $1000{ }^{\circ} \mathrm{C}$, the typical boride morphology transitioned into a smooth metallic-looking structure. At higher temperatures, above $1100{ }^{\circ} \mathrm{C}$, the surface revealed coalesced regions of varying contrast attributed to metallic cobalt and crystalline tungsten carbide and borides (as measured by EDS).

Analysis by AFM provided a quantitative measurement of the surface roughness for these samples (not shown). Untreated WC-Co polished down to 1 micron grit contained pitted features resulting in an average surface roughness $\left(\mathrm{R}_{\mathrm{a}}\right)$ of $150 \mathrm{~nm}$. These features were reduced during the boriding process. Borided surfaces prepared at 800,900 and $1000{ }^{\circ} \mathrm{C}$ showed significant variation in surface roughness. At $800{ }^{\circ} \mathrm{C}$ the surface roughness measured $75 \mathrm{~nm}$, with height profile $\left(R_{t}\right)$ of $1000 \mathrm{~nm}$. This roughness is diminished at $900{ }^{\circ} \mathrm{C}$ to $50 \mathrm{~nm} R_{a}$ and $600 \mathrm{~nm} R_{t}$. Further increase in temperature to $1000{ }^{\circ} \mathrm{C}$ resulted in decreased roughness $\left(\mathrm{R}_{\mathrm{a})}\right.$ to $40 \mathrm{~nm}$ and $\mathrm{R}_{\mathrm{t}}$ of $500 \mathrm{~nm}$. Higher temperatures seem to result in more coalesced films, with reduced surface roughness.

\subsection{Nanoindentation Hardness}

Nanoindentation was used to evaluate the hardness, modulus and elastic vs. plastic depth for polished WC-Co and WC-Co borided at 700-1100 ${ }^{\circ} \mathrm{C}$ in $100{ }^{\circ} \mathrm{C}$ increments. The data with error bars represent average and standard deviation for $n=100$ indents ( 20 indents on 5 samples at each temperature). Tests on the un-borided alloy to $400 \mathrm{~nm}$ depth show an average hardness of $23 \pm 1 \mathrm{GPa}$, and elastic modulus of $660 \pm 20 \mathrm{GPa}$. For all temperatures, the surface of the borided alloy shows increased hardness ranging from $25 \pm 2 \mathrm{GPa}$ to $28 \pm 2 \mathrm{GPa}$ and elastic modulus ranging from $600 \pm 20 \mathrm{GPa}$ to $780 \pm 20 \mathrm{GPa}$ at $400 \mathrm{~nm}$ depth (Figure $5 \mathrm{a}$ and $5 \mathrm{~b}$ ). From the glancing-angle XRD data, the surface hardness is expected to result from a mixture of the constituent metal-borides.

Some level of variation exists due to the rough nature of ceramic tungsten carbide. Even when polished to a mirror finish, the ceramic material has an inhomogeneous grain structure that results in inconsistent nano-scale hardness measurements. Furthermore, the carbides have a porous and pitted surface that was only partly filled in by boriding. Nevertheless, a clear increase in hardness and elastic modulus is observed at many boriding temperatures, as expected. Substrate effects are reduced by using an indent depth of less than $10 \%$ of the surface coating 
thickness. The effect of adjacent indents is reduced by using an indent spacing of 25 microns, a distance many times greater than the indent depth. The distance from the sample edge is greater than 100 microns, reducing edge effects. Due to the consistency in the elastic modulus between the coating and the substrate, plastic flow of coating compared to substrate or vice-versa should not be significant.

The as provided carbide is expected that have a hardness of $14.7 \mathrm{GPa}[20]$ for medium grained carbide. Our tests on the carbide show a control hardness of $23 \pm 1 \mathrm{GPa}$. This discrepancy is likely the result of polishing the surface down to a 1 micron roughness, creating a surface that is more in line with a finer grain structure which have known hardness as high as 23 $\mathrm{GPa}[20]$. As-received carbides have an expected elastic modulus (young's modulus) of 640 $\mathrm{GPa}[20]$, this agrees with our measured value of $660 \pm 20 \mathrm{GPa}$. Previously reported values for WCoB hardness vary, but include values from $23.4 \mathrm{GPa}[11]$ to $45 \mathrm{GPa}[19]$. Our data falls within this range with data points as high as $45 \mathrm{GPa}$. Studies involving $\mathrm{WCoB}$ and $\mathrm{W}_{2} \mathrm{CoB}_{2}$ often evaluate its hardness as a component of bulk ceramic material rather than a surface coating, and report a hardness of 89-90 (HRA)[33] and 84.4-92.2 (HRA)[34].

\subsection{Surface Adhesion}

Progressive load scratch tests were used to study the adhesion of boride coatings on the WC-Co substrate. A typical result is presented in Figure 6. Scratch testing was performed for 5 samples of each $800{ }^{\circ} \mathrm{C}, 900{ }^{\circ} \mathrm{C}$, and $1000{ }^{\circ} \mathrm{C}$, with 5 scratches per sample for a total of $\mathrm{n}=25$ tests per temperature. The $\mathrm{CoB}$ and $\mathrm{WCoB}\left(800^{\circ} \mathrm{C}\right)$ layer shows cohesive failure at $28 \mathrm{~N} \pm 3 \mathrm{~N}$ (arc tensile cracking) and adhesive failure at $34 \mathrm{~N} \pm 3 \mathrm{~N}$ (edge spallation) and $50 \mathrm{~N} \pm 3 \mathrm{~N}$ (buckling spallation). The $\mathrm{W}_{2} \mathrm{CoB}_{2}\left(900{ }^{\circ} \mathrm{C}\right.$ ) layer shows cohesive failure at $37 \mathrm{~N} \pm 3 \mathrm{~N}$ (arc tensile cracking) and adhesive failure at $42 \mathrm{~N} \pm 5 \mathrm{~N}$ (edge spallation) and $65 \mathrm{~N} \pm 7 \mathrm{~N}$ (buckling spallation). The WCoB $\left(1000{ }^{\circ} \mathrm{C}\right.$ ) layer shows cohesive failure at $42 \mathrm{~N} \pm 2 \mathrm{~N}$ (arc tensile cracking) and adhesive failure at $48 \mathrm{~N} \pm 8 \mathrm{~N}$ (edge spallation) and $72 \mathrm{~N} \pm 4 \mathrm{~N}$ (buckling spallation).

Cohesive failure was below the threshold for the acoustic signal, and was determined by secondary optical examination. Figure $6 \mathrm{c}$ shows the region of cohesive failure with arc tensile cracking along the edges of the scratch. Arc tensile cracking is attributed to tensile stress pulling apart the boride coating as the scratch propagates. Adhesive failure is indicated by a sharp rise in drag coefficient then acoustic signal in Figure 6a. This is attributed to significant edge recovery spallation (Figure 6e), followed by interface buckling spallation (Figure $6 \mathrm{~b}$ an 6d). Edge spallation is the result of significant plastic and elastic deformation which has a maximum deformation along the edge of the scratch. Buckling spallation occurs when the combined transverse and normal load are sufficient to simultaneously overcome the adhesive bonding and cohesive strength of the film[25]. The drag coefficient seen in Figure 6a, is a function of the measured transverse load on the indenter and the applied normal load. It is not a measure of the sliding coefficient of friction. The transverse load, and thus the drag coefficient is expected to increase as scratch depth increases as a result of increased "plowing" into the material. The sudden increase in drag coefficient seen at $5 \mathrm{~mm}$ is likely due to edge spallation and build-up of debris along the scratch path. The spike in acoustic signal at $7.5 \mathrm{~mm}$ is due to buckling spallation. These patterns are consistent with a hard film on a hard substrate[25]. 
Residual scratch depth is estimated by SEM observation to be $70 \mu \mathrm{m}$. Cracks and surface delamination did not propagate beyond the scratch indicating a well adhered surface film. The increase in load for adhesive failure with deposition temperature may be the result of increased metal-boride formation within the carbide surface as temperature increased. As shown by EDS, boron diffuses into bulk material and higher temperatures are expected to increase ion diffusion and interaction within the substrate. Also, there is a distinct boride phase difference at each of these temperatures; adhesion to the surface may be the result of each specific phase. An estimation of residual surface stress for each phase is made difficult by a complex phase mixture of borides with uncertain coefficients of thermal expansion. A best estimate of residual surface stress ranges from 1 to $4 \mathrm{GPa}$. The $\mathrm{WCoB}\left(1000{ }^{\circ} \mathrm{C}\right)$ layer can be more accurately estimated at $3.2 \pm .3 \mathrm{GPa}[35,36]$. In all cases this stress is expected to be partially relieved by the surface microfractures seen in Figure 3a.

\section{Conclusion}

These results show distinct temperature-sensitive phase transformations for PECVD metal-borides on WC-Co. This expands on previous data via a more detailed evaluation of phase evolution with temperature showing a detailed transition between phases. The PECVD process results in ternary borides that are consistent with other boriding techniques. Plasma boriding of tungsten carbide at surface temperatures from 600-1200 resulted in an array of metal-boride surface layers, including ternary borides, which exhibited increased hardness and elastic modulus with excellent surface adhesion. The borides that formed include: orthorhombic $\mathrm{CoB}, \mathrm{WCoB}$, $\mathrm{W}_{2} \mathrm{CoB}_{2}$ and $\mathrm{BCo}_{3}$, Hexagonal $\mathrm{B}_{2} \mathrm{~W}$ and Tetragonal $\mathrm{B}_{2} \mathrm{~W}$. Boriding temperatures below $800{ }^{\circ} \mathrm{C}$ resulted in loosely adhered soot composed of mixed orthorhombic $\mathrm{CoB}$ and orthorhombic WCoB. At $800{ }^{\circ} \mathrm{C}$ a coalesced, adhered film of equal parts $\mathrm{WCoB}$ and $\mathrm{CoB}$ was formed. Hardness and modulus at $800{ }^{\circ} \mathrm{C}$ was $26 \pm 2 \mathrm{GPa}$ and $604 \pm 20 \mathrm{GPa}$ respectively. At $850{ }^{\circ} \mathrm{C}$ the surface coating was $\mathrm{W}_{2} \mathrm{CoB}_{2}$ and equal parts $\mathrm{WCoB}$ with a hardness and modulus of $29 \pm 2 \mathrm{GPa}$ and $760 \pm 20 \mathrm{GPa}$. Samples prepared at $900{ }^{\circ} \mathrm{C}$ had a $\mathrm{W}_{2} \mathrm{CoB}_{2}$ surface structure with less than $4 \%$ each of hexagonal and tetragonal $\mathrm{WB}_{2}$. Thin surface hardness and modulus values were $27 \pm$ $2 \mathrm{GPa}$ and $710 \pm 20 \mathrm{GPa}$, respectively. This composition transitioned into primarily $\mathrm{WCoB}$ at $1000{ }^{\circ} \mathrm{C}$ with a hardness and modulus of $26 \pm 2 \mathrm{GPa}$ and $651 \mathrm{GPa}$. Above $1100{ }^{\circ} \mathrm{C}$ surface borides gave way to substrate tungsten carbide and cobalt phases. Cross-sectional electron dispersive spectroscopy confirmed the elemental constituents at the surface and showed a boron surface layer of 3-5 microns depth and boron diffusion into the carbide grain structure. Scanning electron microscopy revealed a smooth boride surface that filled in the natural porous structure of sintered WC-Co. Micro fracturing on the boride surface may have helped to relieve residual thermal stress thereby preventing delamination of the boride layers. Scratch testing resulted in cohesive failure at $28 \mathrm{~N} \pm 3 \mathrm{~N}$ and adhesive failure at $34 \mathrm{~N} \pm 3 \mathrm{~N}$ and $50 \mathrm{~N} \pm 3 \mathrm{~N}$ for $\mathrm{CoB}$ and $\mathrm{WCoB}$, cohesive failure at $37 \mathrm{~N} \pm 3 \mathrm{~N}$ and adhesive failure at $42 \mathrm{~N} \pm 5 \mathrm{~N}$ and $65 \mathrm{~N} \pm 7 \mathrm{~N}$ for $\mathrm{W}_{2} \mathrm{CoB}_{2}$, and cohesive failure at $42 \mathrm{~N} \pm 2 \mathrm{~N}$ and adhesive failure at $48 \mathrm{~N} \pm 8 \mathrm{~N}$ and $72 \mathrm{~N} \pm 4 \mathrm{~N}$ for WCoB. These results indicate that the temperature range from $800{ }^{\circ} \mathrm{C}$ to $1000{ }^{\circ} \mathrm{C}$ results in boride treatments that could be used for the strengthening of WC-Co. At least four specific deposition parameters $\left(800{ }^{\circ} \mathrm{C}, 850{ }^{\circ} \mathrm{C}, 900{ }^{\circ} \mathrm{C}\right.$, and $\left.1000{ }^{\circ} \mathrm{C}\right)$ present with unique metal-boride phase mixtures for material enhancement. Furthermore, the dense, coalesced boride structure 
combined with a boron diffusion layer suggests that these films may be promising candidates for future nanostructured diamond deposition experiments.

\section{Acknowledgments}

Our research results are based upon work supported by the National Science Foundation Partnerships for Innovation: Building Innovation Capacity (PFI: BIC) subprogram under Grant No. IIP-1317210. Any opinions, findings, and conclusions or recommendations expressed in this material are those of the author(s) and do not necessarily reflect the views of the National Science Foundation.

\section{References}

[1] Z.Z. Fang, X. Wang, T. Ryu, K.S. Hwang, H. Sohn, Synthesis, sintering, and mechanical properties of nanocrystalline cemented tungsten carbide-a review, International Journal of Refractory Metals and Hard Materials, 27 (2009) 288-299.

[2] J. Arsecularatne, L. Zhang, C. Montross, Wear and tool life of tungsten carbide, PCBN and PCD cutting tools, International Journal of Machine Tools and Manufacture, 46 (2006) 482-491.

[3] I. Campos-Silva, D. Bravo-Bárcenas, A. Meneses-Amador, M. Ortiz-Dominguez, H. Cimenoglu, U. Figueroa-López, J. Andraca-Adame, Growth kinetics and mechanical properties of boride layers formed at the surface of the ASTM F-75 biomedical alloy, Surface and Coatings Technology, 237 (2013) 402-414. [4] P.W. May, Diamond thin films: a 21st-century material, Philosophical Transactions of the Royal Society of London. Series A: Mathematical, Physical and Engineering Sciences, 358 (2000) 473-495. [5] I. Campos-Silva, THE BORIDING PROCESS: GROWTH KINETICS AND MECHANICAL CHARACTERIZATION OF BORIDE LAYERS, in: International Iron \& Steel Symposium, Karabük, Türkiye, 2012, pp. 27-35.

[6] X. Chen, J. Narayan, Effect of the chemical nature of transition-metal substrates on chemical-vapor deposition of diamond, Journal of Applied Physics, 74 (1993) 4168-4173.

[7] J.G. Buijnsters, P. Shankar, P. Gopalakrishnan, W.J.P. van Enckevort, J.J. Schermer, S.S. Ramakrishnan, J.J. ter Meulen, Diffusion-modified boride interlayers for chemical vapour deposition of low-residualstress diamond films on steel substrates, Thin Solid Films, 426 (2003) 85-93.

[8] U. Sen, S. Sen, The fracture toughness of borides formed on boronized cold work tool steels, Materials Characterization, 50 (2003) 261-267.

[9] W. Tang, Q. Wang, S. Wang, F. Lu, A comparison in performance of diamond coated cemented carbide cutting tools with and without a boride interlayer, Surface and Coatings Technology, 153 (2002) 298-303.

[10] W. Tang, S. Wang, F. Lu, Preparation and performance of diamond coatings on cemented carbide inserts with cobalt boride interlayers, Diamond and Related Materials, 9 (2000) 1744-1748.

[11] Zakhariev, New superhard ternary borides in composite materials, INTECH Open Access Publisher, 2011.

[12] M. Ulutan, M.M. Yildirim, O. Ãłelik, S. Buytoz, Tribological Properties of Borided AISI 4140 Steel with the Powder Pack-Boriding Method, Tribology Letters, 38 (2010) 231-239.

[13] J.R. Davis, Surface hardening of steels: understanding the basics; $\mathrm{CH} .8$ Boriding, in, ASM International, Materials Park, OH, 2002, pp. 213-216.

[14] D. Mercurio-Lavaud, K. Petrov, P. Peshev, Z. Zakhariev, The elemental and phase composition of boride coatings deposited by diffusion on a WC-Co alloy, Journal of the Less Common Metals, 67 (1979) 59-63.

[15] Z. Zakhariev, K. Petrov, M. Christov, Preparation and some properties of boride diffusion layers on hard WC TiC Co alloys, Journal of the Less Common Metals, 82 (1981) 57-62. 
[16] C. Martini, G. Palombarini, G. Poli, D. Prandstraller, Sliding and abrasive wear behaviour of boride coatings, Wear, 256 (2004) 608-613.

[17] S. Köksal, The Characterization of WC-Co Based Materials Boronized within Molten Salt Bath, in: Solid State Phenomena, Trans Tech Publ, 2009, pp. 261-266.

[18] J.M. Johnston, M. Jubinsky, S.A. Catledge, Plasma boriding of a cobalt-chromium alloy as an interlayer for nanostructured diamond growth, Applied Surface Science, 328 (2015) 133-139.

[19] A. Saez, F. Arenas, E. Vidal, Microstructure development of WCoB-TiC based hard materials, International Journal of Refractory Metals and Hard Materials, 21 (2003) 13-18.

[20] Sandvik Group. (2015). Understanding Cemented Carbide. Available from:

http://www.sandvik.com/en/

[21] ICDD (2001). PDF-2 2001 (Database), International Centre for Diffraction Data, Newtown Square, PA, USA

[22] S. Gražulis, A. Daškevič, A. Merkys, D. Chateigner, L. Lutterotti, M. Quirós, N.R. Serebryanaya, P. Moeck, R.T. Downs, A. Le Bail, Crystallography Open Database (COD): an open-access collection of crystal structures and platform for world-wide collaboration, Nucleic Acids Research, 40 (2012) D420D427.

[23] University of Trento. (2015). MAUD. Available from: http://nanoair.dii.unitn.it:8080/maud/

[24] H. Rietveld, A profile refinement method for nuclear and magnetic structures, Journal of applied Crystallography, 2 (1969) 65-71.

[25] S.T. Gonczy, N. Randall, An ASTM standard for quantitative scratch adhesion testing of thin, hard ceramic coatings, International Journal of Applied Ceramic Technology, 2 (2005) 422-428.

[26] Y. Wang, Y. Ma, F.H. Sun, Z.M. Zhang, M. Chen, Deposition of Diamond Films on Smooth Surfaces of Cemented Carbide Inserts with Cobalt Boride Interlayers, in: Key Engineering Materials, Trans Tech Publ, 2006, pp. 205-209.

[27] Q.-p. Wei, Z. Yu, M.N. Ashfold, J. Ye, L. Ma, Synthesis of micro-or nano-crystalline diamond films on WC-Co substrates with various pretreatments by hot filament chemical vapor deposition, Applied Surface Science, 256 (2010) 4357-4364.

[28] W.D. Nix, Mechanical properties of thin films, Metallurgical and Materials Transactions A, 20 (1989) 2217-2245.

[29] M. Huang, Z. Suo, Q. Ma, H. Fujimoto, Thin film cracking and ratcheting caused by temperature cycling, Journal of Materials Research, 15 (2000) 1239-1242.

[30] E. Rodrı, G. Laudien, S. Biemer, K.-T. Rie, S. Hoppe, Plasma-assisted boriding of industrial components in a pulsed dc glow discharge, Surface and Coatings Technology, 116 (1999) 229-233.

[31] G.S. Upadhyaya, Cemented Tungsten Carbides: Production, Properties and Testing, Elsevier Science, 1998.

[32] F.C. Nix, F.E. Jaumot Jr, Experimental Evidence for the Vacancy Mechanism in Diffusion in Metals and Alloys, Physical Review, 83 (1951) 1275.

[33] D. Ke, Y. Pan, X. Lu, B. Hong, H. Zhang, Influence and effectivity of Sm 203 and Cr 3 C 2 grain growth inhibitors on sintering of WCoB-TiC based cermets, Ceramics International, (2015).

[34] P. Yingjun, X. Ming, H. Bing, R. Xiaolin, Preparation and properties of WCoB cermet, Journal of Wuhan University of Science and Technology, 2 (2011) 005.

[35] K. Petrov, G. Will, X-ray diffraction measurement of the linear thermal expansion coefficients of WCoB in the range 300 to $973 \mathrm{~K}$, Journal of Materials Science, 16 (1981) 3218-3220.

[36] L.B. Freund, S. Suresh, Thin film materials: stress, defect formation and surface evolution, Cambridge University Press, 2004. 


\section{Figure Captions}

Figure 1: XRD scans of the metal-boride surface layer for a range of substrate temperatures. Threedegree glancing angle XRD shows the formation of orthorhombic $\mathrm{CoB}, \mathrm{WCoB}, \mathrm{W}_{2} \mathrm{CoB}_{2}$ and $\mathrm{BCo}_{3}$, Hexagonal $\mathrm{B}_{2} \mathrm{~W}$ and Tetragonal $\mathrm{B}_{2} \mathrm{~W}$ on the WC-Co substrate for $700-1100{ }^{\circ} \mathrm{C}$ using 100 -degree intervals. No boride compounds were present in the control sample.

Figure 2: Evolution of surface phase with temperature. Rietveld analysis of phase composition vs temperature shows the transition from bulk WC-Co to various cobalt boride phases as temperature increases. Phases shown included hexagonal WC, hexagonal $\mathrm{Co}$, orthorhombic $\mathrm{CoB}$, orthorhombic $\mathrm{W}_{2} \mathrm{CoB}_{2}$, and orthorhombic $\mathrm{WCoB}$. Each point represents an average with standard of deviation for $\mathrm{n}=5$ samples prepared under identical conditions.

Figure 3: Scanning electron microscopy and energy dispersive spectroscopy of boride on WC-Co. Figures 3 a-c are a false color SEM scan of backscattered electrons (blue) and secondary emission (yellow). (a) SEM scan of the boride surface shows micro-cracks across the entire coating. (b) Crosssection image shows a smooth, thin $(\sim 3-5 \mu \mathrm{m}) \mathrm{WCoB}$ coating on the rough porous substrate. SEM and EDS performed on the cross-sectional face reveal the grain structure of the ceramic material. The solid red line is an indicator for Figure 3d (c) Figure 3c shows a higher contrast cross sectional image with a more clear distinction between the boride layer and the substrate. (d) An EDS line scan of the crosssectioned, borided WC-Co, corresponding to the line scan on Figure 3b. This shows boron diffusion into the bulk carbide and significantly increased concentration in the surface layer. Relative tungsten concentration decreases toward the surface. Cobalt is present throughout, but also is present in high concentration areas between defined carbide grains. The interface between the boron surface layer and the bulk material, indicated by the red vertical line, shows an increase in boron near the surface.

Figure 4: 1000X magnification of borided WC 600-1200 ${ }^{\circ} \mathrm{C}$ : Optical images of surface boride show variation in surface roughness and contrast for (a) $600{ }^{\circ} \mathrm{C}$ (b) $800{ }^{\circ} \mathrm{C}$ (c) $1000^{\circ} \mathrm{C}$ (d) $1200{ }^{\circ} \mathrm{C}$

Figure 5: Nanoindentation hardness and modulus. Nanoindentation hardness testing on the polished WC show an average bulk hardness of $23 \pm 1 \mathrm{GPa}$ and modulus of $660 \pm 20 \mathrm{GPa}$, indicated as an open diamond symbol in figures a. and b. (a.) The average hardness measured at $400 \mathrm{~nm}$ for boron treated WC-Co vs temperature ranges from $25 \pm 2 \mathrm{GPa}$ at $1100{ }^{\circ} \mathrm{C}$ to $28 \pm 2 \mathrm{GPa}$ at $850{ }^{\circ} \mathrm{C}$ (b.) The average modulus measured at $400 \mathrm{~nm}$ ranges from $600 \pm 20 \mathrm{GPa}$ at $800{ }^{\circ} \mathrm{C}$ to $780 \pm 20 \mathrm{GPa}$ at $850{ }^{\circ} \mathrm{C}$. In all cases vertical error bars have been calculated using the standard of deviation $(n=100)$.

Figure 6: Progressive load scratch testing of borided WC-Co. (a.) An optical image of progressive load scratch testing for adhesion is shown above the corresponding scratch tester normal load (dotted line), drag coefficient (dashed line), and acoustic signal (solid line). Y-axis units of force apply to normal load and transverse load; the acoustic signal has been scaled to fit. Cohesive failure is observed around $40 \mathrm{~N}$ (no acoustic signal). At $52 \mathrm{~N}$ edge recovery spallation results in increased drag coefficient. Near $78 \mathrm{~N}$, adhesive failure occurs, indicated by acoustic signal. (b.) Optical microscopy shows buckling spallation indicative of adhesive failure of a hard film on a hard substrate. (c.) Cohesive failure, shown by optical microscopy, resulted in cracking of the boride layer along the scratch edges. (d.) A 5kv secondary electron SEM scan shows another example of buckling spallation in the central scratch area. (e.) A $5 \mathrm{kv}$ secondary electron SEM scan of the scratch sides reveals adhesive failure cracking and recovery spallation. The residual scratch depth is determined to be $70 \mu \mathrm{m}$. No long range surface delamination is observed. 


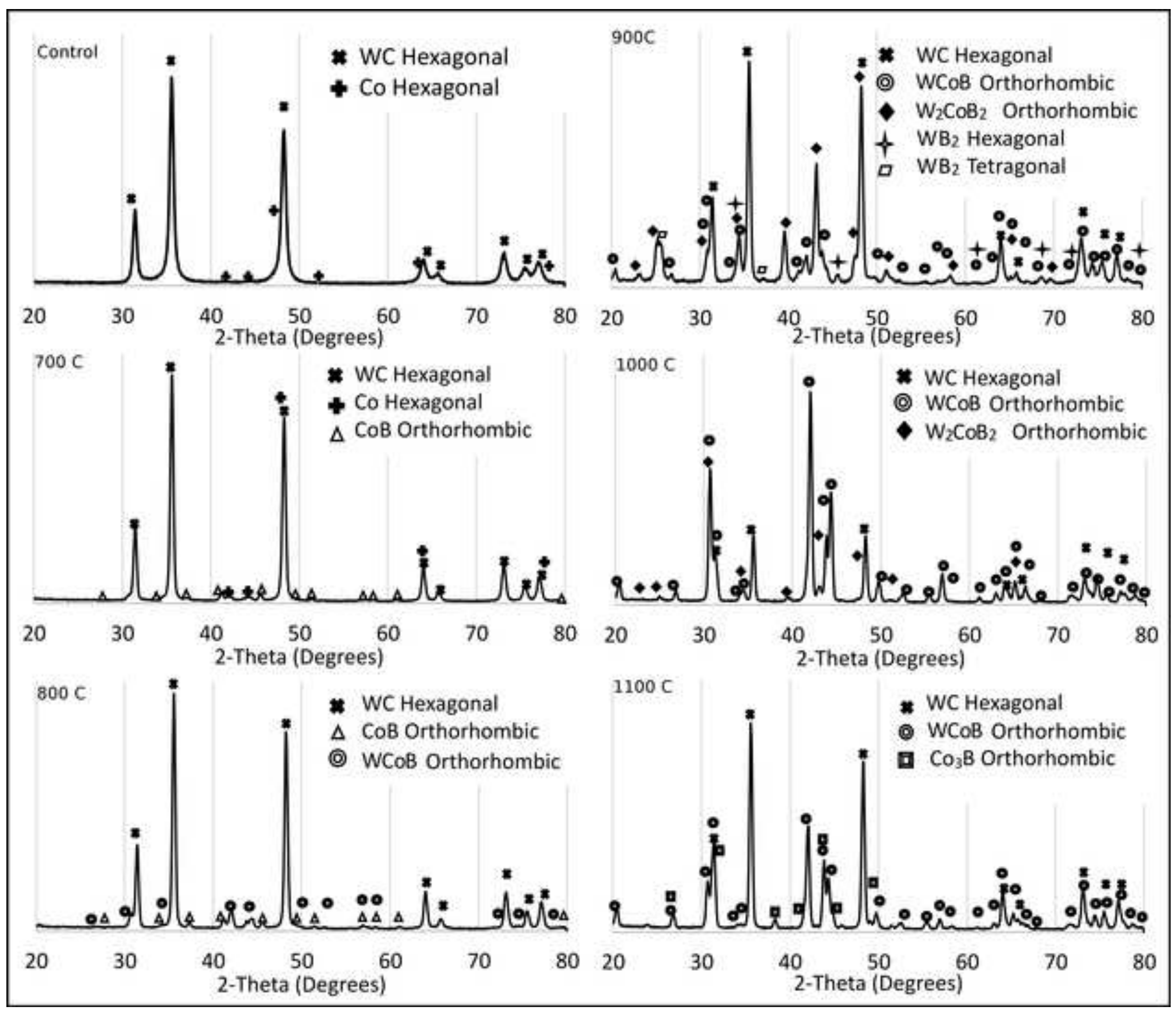




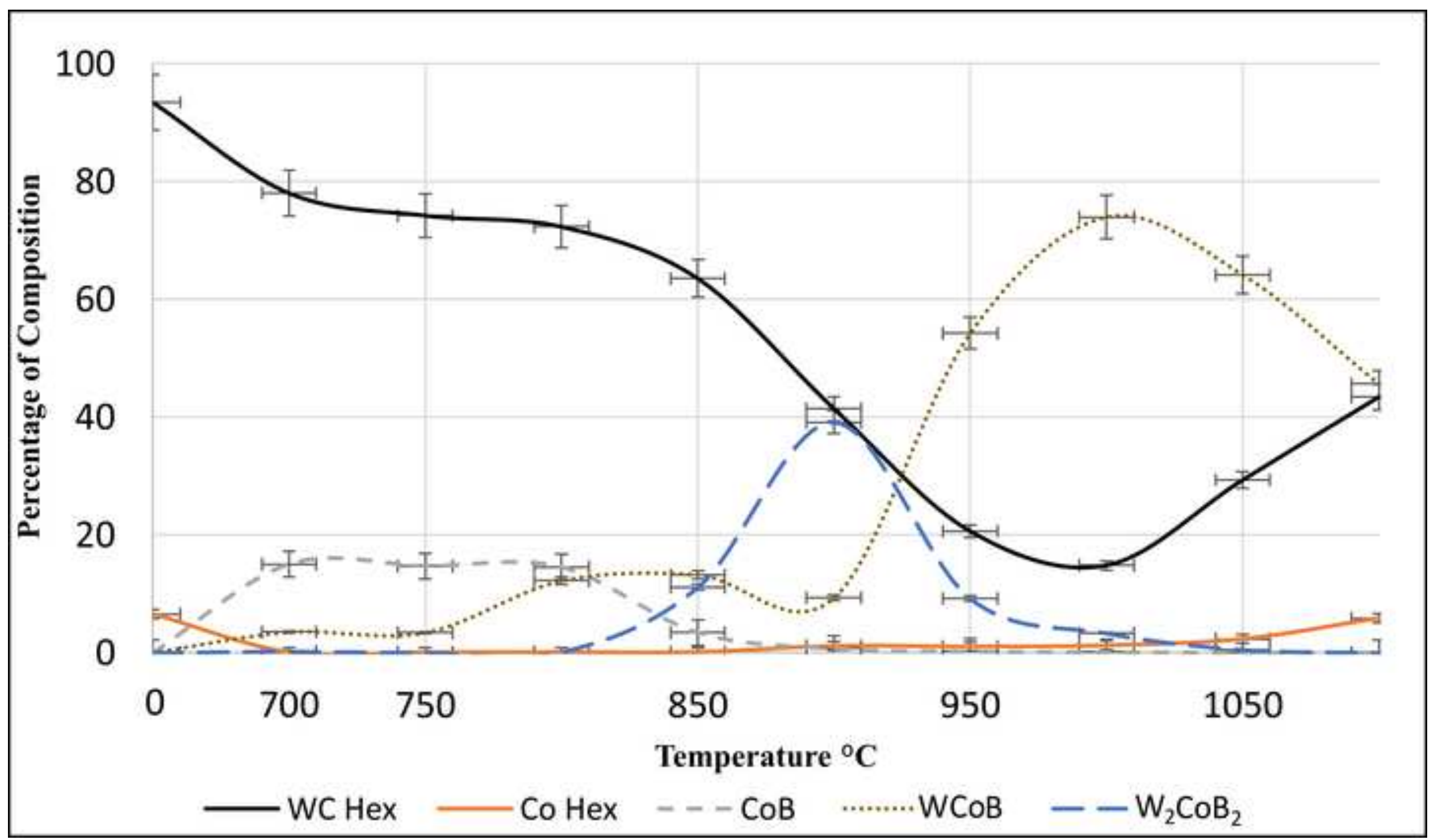



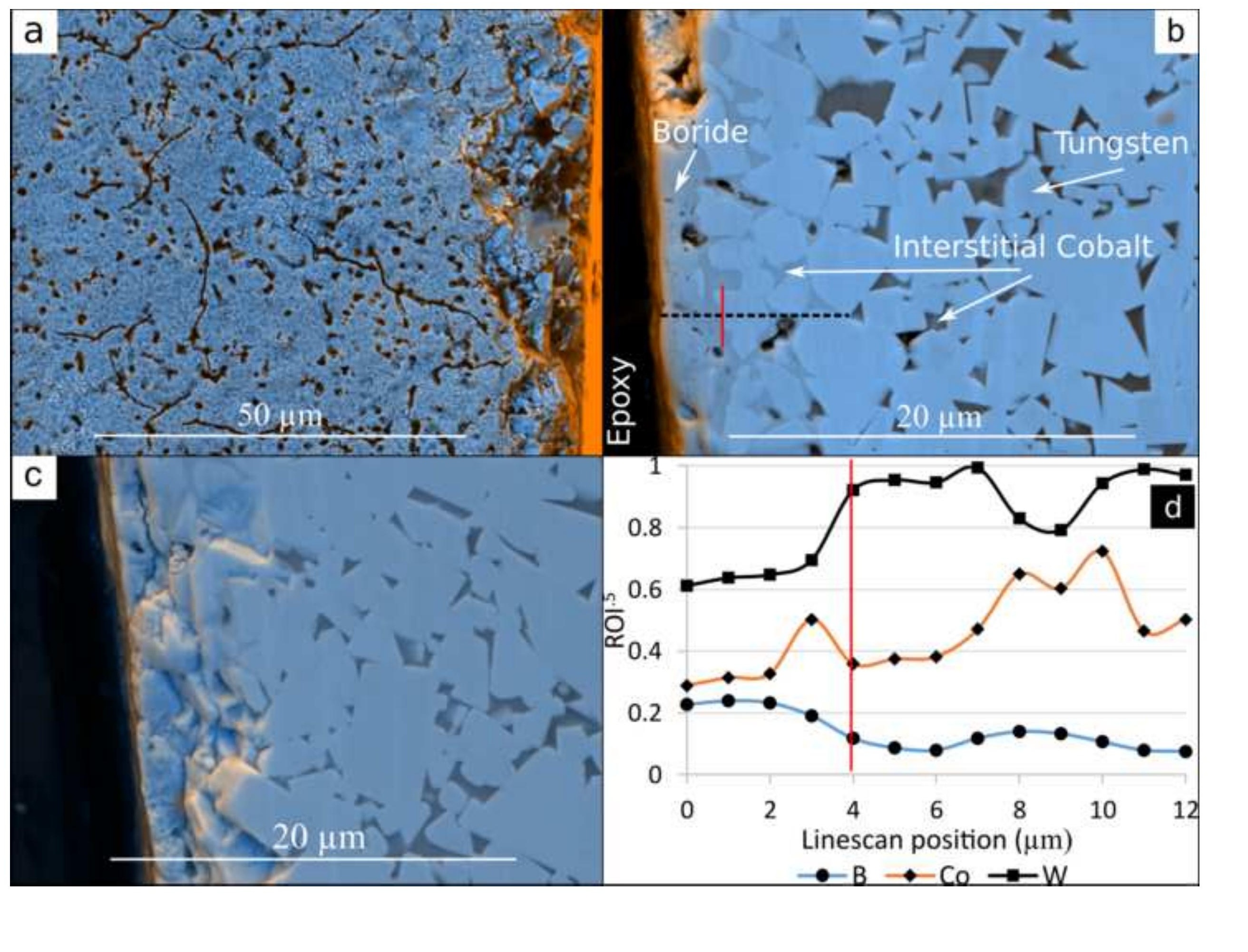


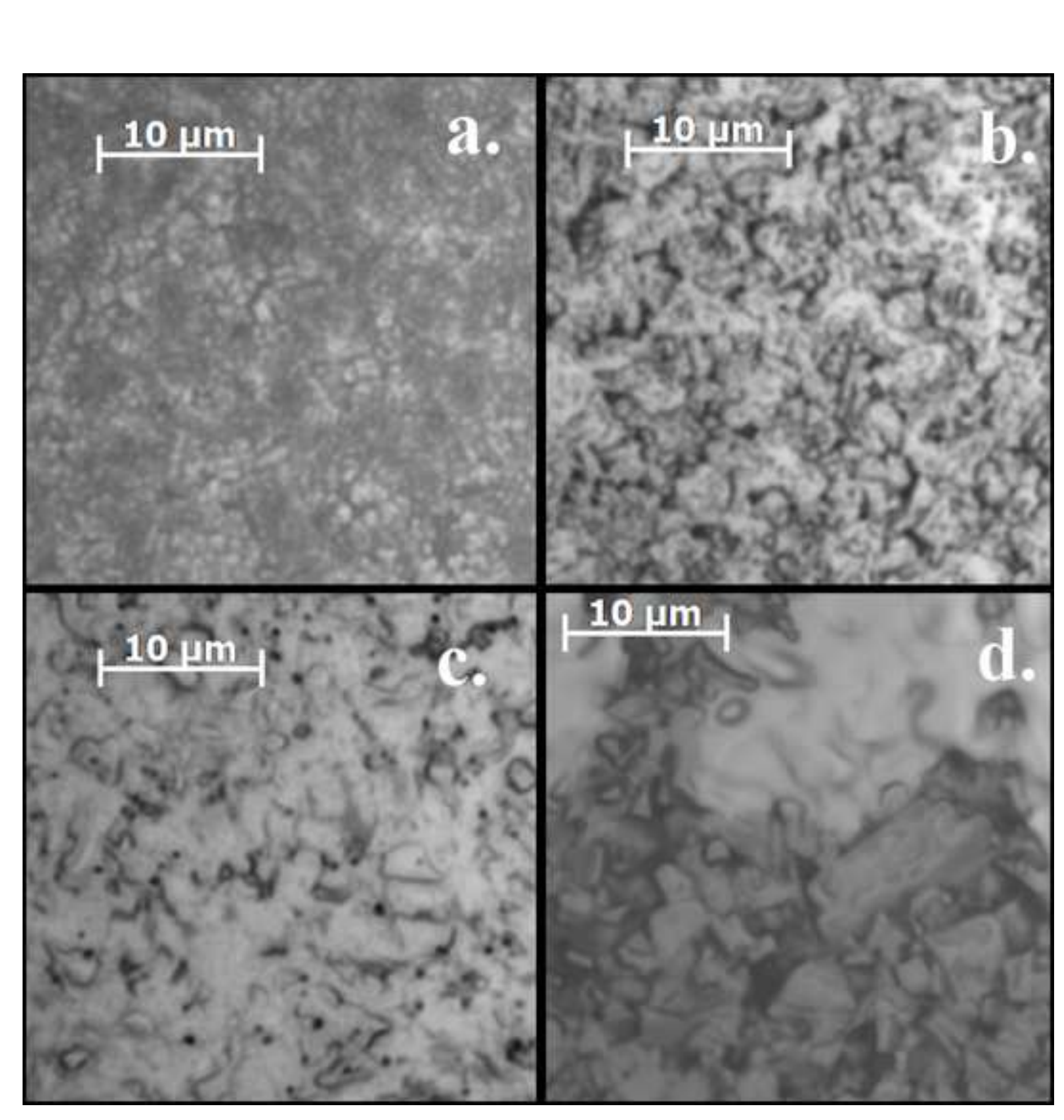

Figure 4

,

Figure 4

4

$10 \mu \mathrm{m}$

(

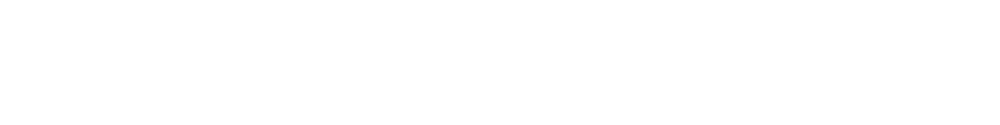




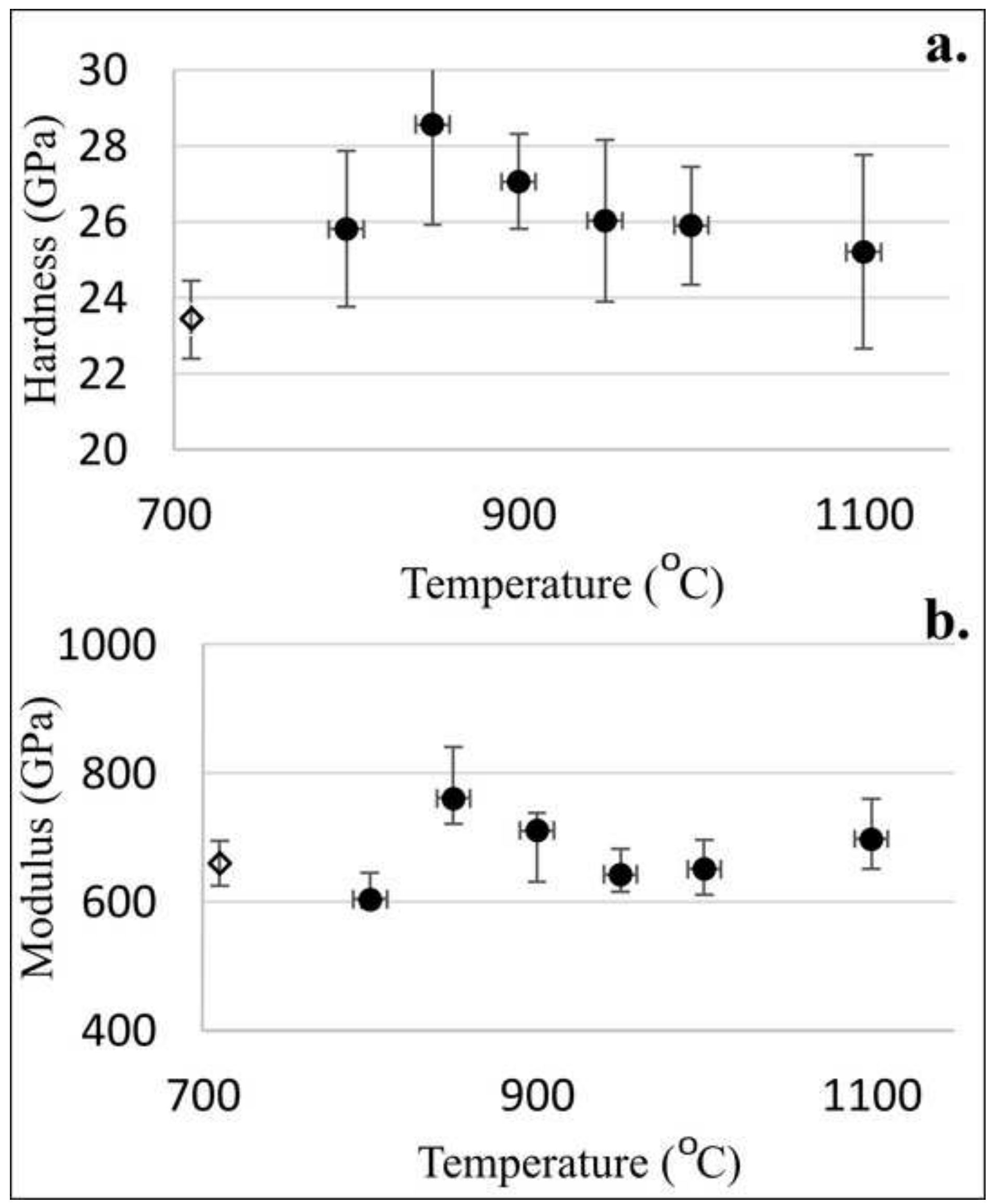

Figure 5

\section{Temperature $\left({ }^{\circ} \mathrm{C}\right)$}

1000

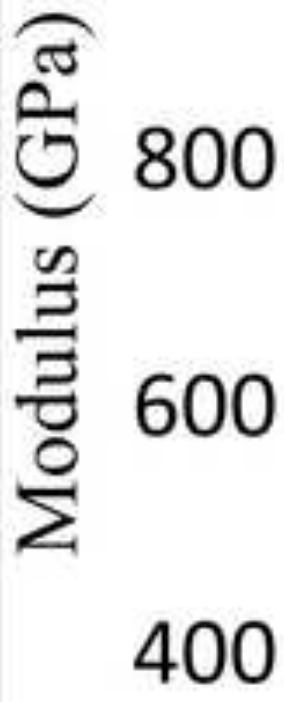

700

900

1100

Temperature $\left({ }^{\circ} \mathrm{C}\right)$ 


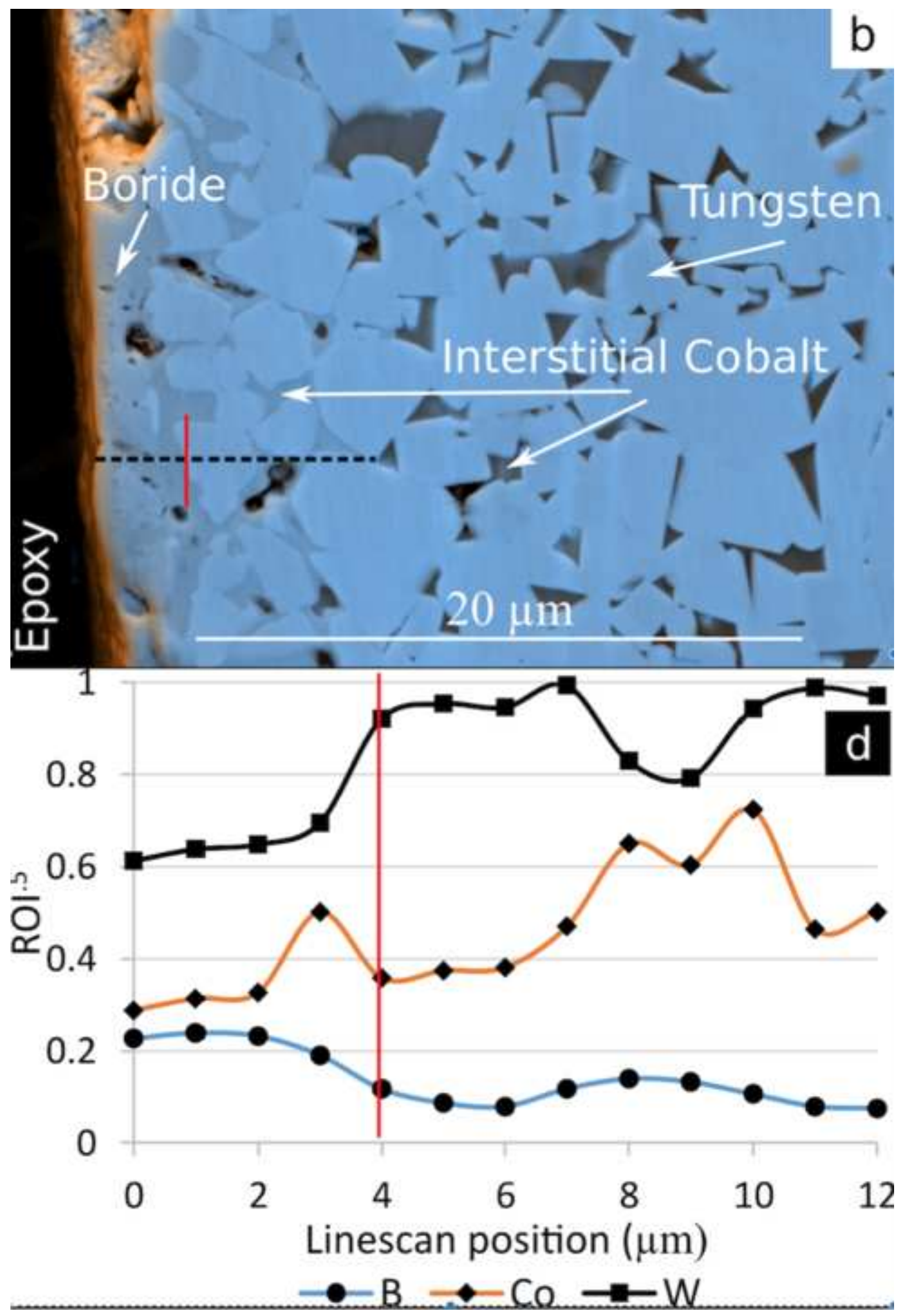

